\title{
Enhancement of Efficiency of the Magnetic Suspension of Belt Conveyor
}

\author{
Zacharov Aleksandr Ju. ${ }^{\text {, }}$, Chepikov Pavel V. ${ }^{\mathrm{b}}$ \\ T. F. Gorbachev Kuzbass State Technical University, \\ Kemerovo, Russian Federation. \\ aauzaharov@rambler.ru, bof.chernigovka@mail.ru
}

\begin{abstract}
Transportation of large pieces of rock hauled on the belt conveyor causes fatigue wearness of the belt rollers. It has been proposed to upgrade the system of magnetic suspension using alteration of the direction of the magnetization vector of the permanent and levitating magnets in conveyor where there are no load-bearing rollers, and there is dual-magnetic suspension. Three layout schemes of the permanent and levitating magnets with axial placement of the magnetization vector, with a layout of the vector at forty-five degrees angle and a Halbach array of five segments have been reviewed. For each scheme, distribution of the magnetic field in plane at $0,5 \mathrm{~mm}$ distance from the surface of the permanent magnets has been obtained. The repulsive force at parallel position of the permanent and levitating magnets at a distance of $1 \mathrm{~mm}$ has been obtained.
\end{abstract}

Keywords - belt conveyor, magnetic suspension, change the direction of magnetization of the permanent magnets

\section{Introduction}

Roller-belt conveyors have a significant shortcoming, i.e. at transportation of lumpy rocks the operational life of the belts and rollers is greatly reduced due to the dynamic loads on the carrying idlers so the restrictions are imposed on the size of the rock pieces, besides economic indicators go down too. In this regard, nowadays active developments to create a belt conveyor without rollers with mechanical, pneumatic or magnetic suspension of belt capable to transport rock without secondary crushing are carried out. [1] Currently, the developed countries including the Russian Federation pay much attention to the development and construction of magnetic systems to create levitation for stationary devices, as well as in vehicles [2][3]. From the viewpoint of energy saving the preferred structure, comparing to the electromagnetic suspension and superconductivity systems, is the magnetic suspension assembly with powerful permanent magnets. Quite intense dynamics of the improvement of the magnets based on rare-earth elements should be noted [4]. At development of the magnetic suspension for the conveyor belt the most difficult issues are to ensure steadiness of the levitating system and minimization of the amount of hard magnetic materials due to their significant value [5][6][7].

\section{II.METHODS}

The Kuzbass State Technical University develops a conveyor with dual circuit magnetic suspension for a typical load-carrying belt [8]. The basis of the conveyor (Fig. 1) is the availability of the two symmetrically located hard-magnetcircuits of belt 4, which could be manufactured with embedded strips of rubber ferrite as well as embedded magnets of higher lift capacity and the design size. The operational belt circuits interact with magnetic supports 2 . At such interaction (repulsion of like poles of magnets) a magnetic cushion is creating, as a result operating belts of the hard-magnet-circuit of the belts levitate above the magnetic supports and provide suspension for the load-carrying belt 1 . Vertical side rollers provide centering of the hard-magnet circuit of belts 3 . These circuits are connected in transverse directions by hinges 5 and traverse 6 , on which an ordinary conveyor belt with a load is placed on 1 . On the empty part of the belt the belt and the relevant parts of the hard-magnet circuits with traverses move by regular idlers 7 . Optimization of the bent radius of traverse 6 as per the criteria of the maximum cross-sectional area of load on belt enables to minimize the width of the load-bearing belt.

Studies have shown that when the belt with the embedded magnets doesn't have a direct interaction with the transported lump load, then the mechanical stress in magnets do not exceed the acceptable standards, and lack of shock and vibration loads in the loading / unloading points creates favorable conditions under which there is no alteration in the magnetization of the magnets [9-11].

Altering the number of rows of the permanent and accordingly levitating magnets, and embedded into the circuit belts magnets at the design stage it is possible to achieve the required load capacity for the main conveyor belt. Fig. 1 shows, as an example, a four-row suspension of the hardmagnet circuit of the belt. In addition, it should be noted that load capacity of the conveyor affects power consumption of the material of the permanent magnets.

In this conveyor the transmission of the drag force is possible by utilizing of the traditional drum drive on the loadcarrying belt in combination with the intermediate drive on hard-magnet circuit, for example, known magnet friction and linear motors with permanent magnets of special design.

The task to provide synchronization of work of the doubledrive circuits having intermediate drive has been successfully fulfilled for the cable belt conveyors, which are long time used in the mining industry; also currently an issue of synchronization of the end drive with intermediate drive has been resolved [12]. 


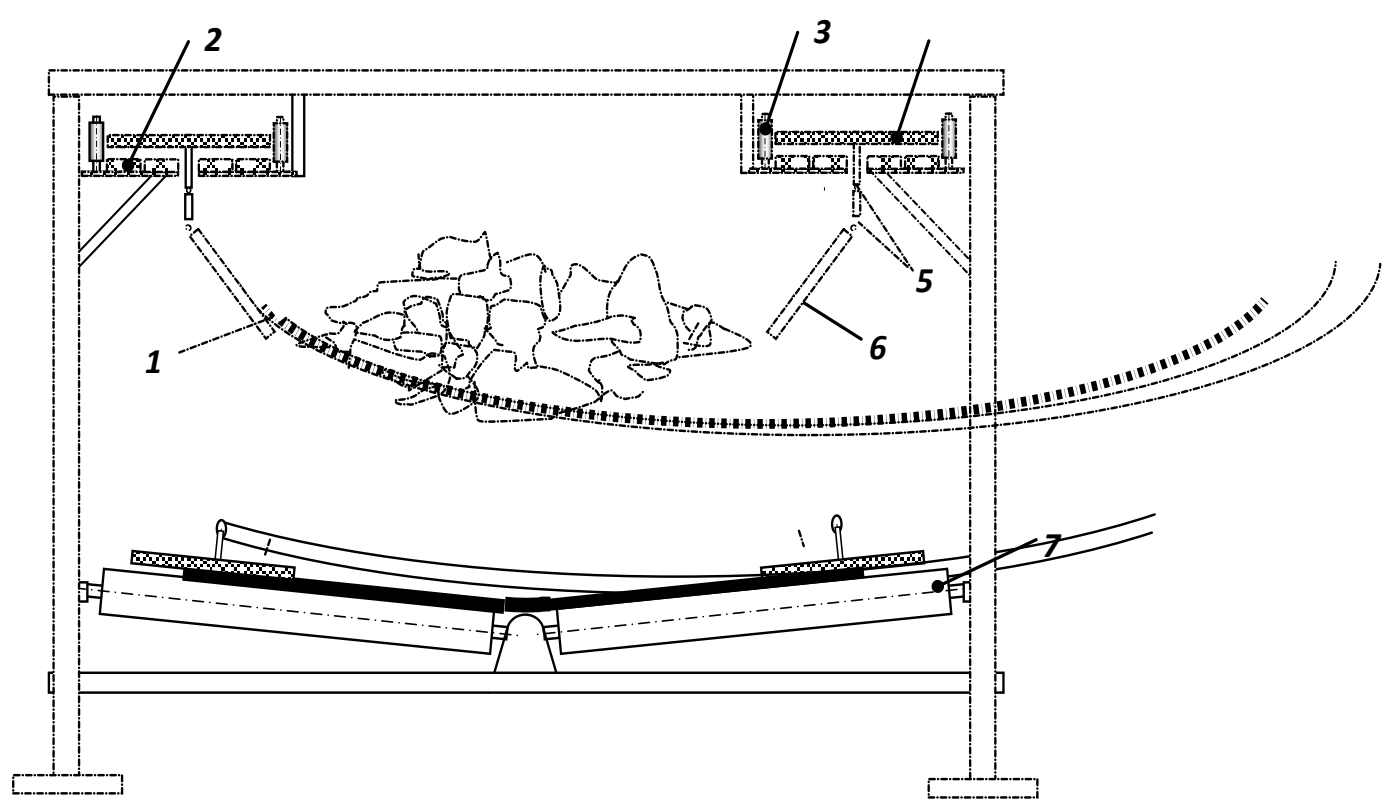

Fig. 1. Scheme of the conveyor cross-section with magnetic suspension for belt transportation of lump of rocks: 1 - load-carrying belt; 2 - magnetic supports; 3 - conveyer guide; 4 - hard-magnetic circuit; 5 - socket-joint; 6 traverse; 7 - standard idler

As already mentioned the load-carrying capacity of the hard-magnet belt, at properly calculation of its data, generally depends on its width and element materials, by means of which the magnetization of the belt is provided. Modern magnetic materials allow provision of the very substantial load capacity, but they have significant value. The reduction of the amount of magnetic material can be done due to optimization of the direction of the magnetization vector.

Due to the different configuration and design features of the suspension, various magnetization directions of the magnets and levitating support systems can be used. Finding the optimum direction of magnetization makes it possible not only to minimize the weight of the permanent magnets, but also make it cheaper and therefore to gain profitability of the installation.

\section{III.RESULTS AND DISCUSSION}

A permanent magnet contains a fixed array of magnetic dipoles, each of which depends on the magnetic field. The total interacting force can be expressed as the sum of forces acting on the individual dipoles. We use general formula of the force applying to the magnetic dipole with magnetic moment $\mathrm{m}$ in an external field:

$$
F=(m \nabla) B=m_{x} \frac{d B}{d x}+m_{y} \frac{d B}{d y}+m_{z} \frac{d B}{d z},
$$

where $m_{x}, m_{y}, m_{z}$, - the date of the projection on the corresponding coordinate axis.

If the dipole in the point where there are no currents produced by the magnetic field, then we can write

$$
F=\operatorname{grad}(m B) \text {. }
$$

Thus, the force of the magnetic interaction will be greatest when all the dipoles, i.e. the magnetization of the magnet, oriented along the force lines of the external field. At production of magnets sintering takes place during extrusion in strongest magnetic field, under the influence of which the magnetic dipole moment happens along the force lines. Therefore, altering configuration of the external field at the moment of sintering, it is possible to change the position of the magnetization vector.

To determine the maximum load-carrying capacity at interaction of the permanent magnets in shape of a cylinder and a ring, a number of suspensions of various magnetization has been considered as per the work of Arvi Kruusing, [13] where it was shown that if to consider load-carrying capacity as $100 \%$ at the axial magnetization, then the variable magnetization along the force lines will be better by $44.2 \%$. But due to the complexity of manufacturing of the magnet another method has been selected with the angle of magnetization as of $45^{\circ}$; which allows improvement of the result by $38.7 \%$. Moreover, there is a recognized principle of combination of magnets with various directions of the magnetization vector - Halbach assembly (Fig. 2). [14 - 17]. 


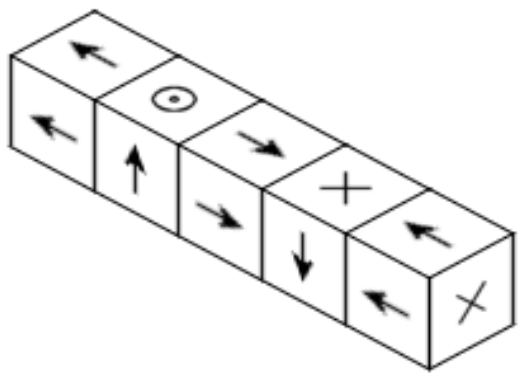

Fig. 2. A linear Halbach assembly consisting of five segments (arrows indicate the direction of magnetization of permanent magnets)

Let us consider three suspension systems: with axial magnetization, magnetization at $45^{\circ}$ angle and Halbach assembly (Fig. 3.). For the adequate comparison of the results the magnets' dimensions were selected in such a way that the volume of the magnets in each system remained constant.

Parameters of magnetic systems:

1. $50 \mathrm{~mm} \times 50 \mathrm{~mm}(4$ pcs., volume $\mathrm{V}=100 \mathrm{~mm} 3)$ with magnetization angle of $45^{\circ}$;

2. $50 \mathrm{~mm} \times 50 \mathrm{~mm}(4$ pcs., volume $\mathrm{V}=100 \mathrm{~mm} 3)$ with axial magnetization;

3. $3.16 \mathrm{~mm} \times 3.16 \mathrm{~mm}(10$ pcs., Volume $\mathrm{V}=$ 99.85mm3) Halbach assembly.

The distance between the magnets of the supporting combination and levitating one is taken as of $1 \mathrm{~mm}$.

Applying the finite element method implemented in the software package ANSOFT Maxwell 3D, the intensity of magnetic field in every suspension system under consideration has been determined.

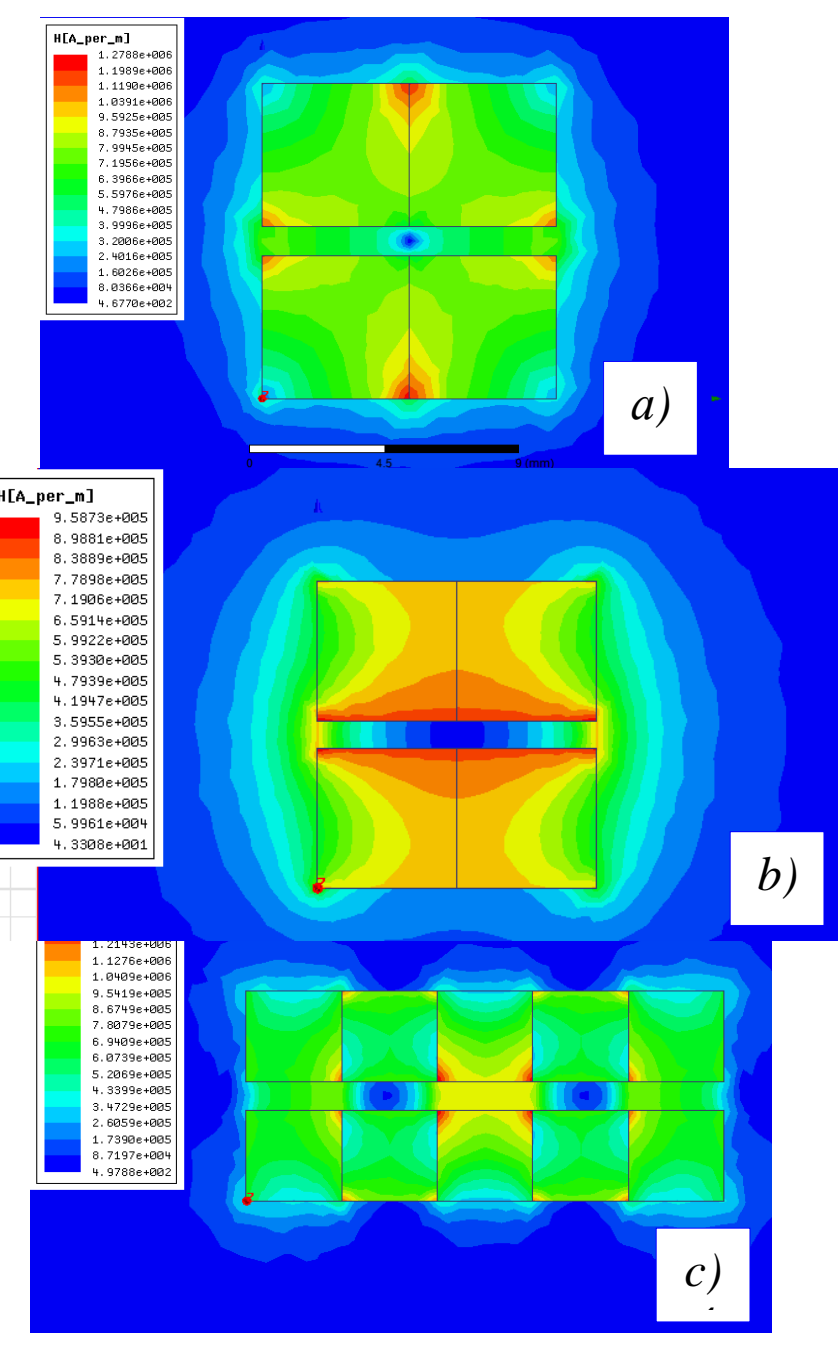

Fig. 3. Intensity of field is: a) with axial magnetization, b) at magnetization angle $45^{\circ}$, c) with Halbach assembly.

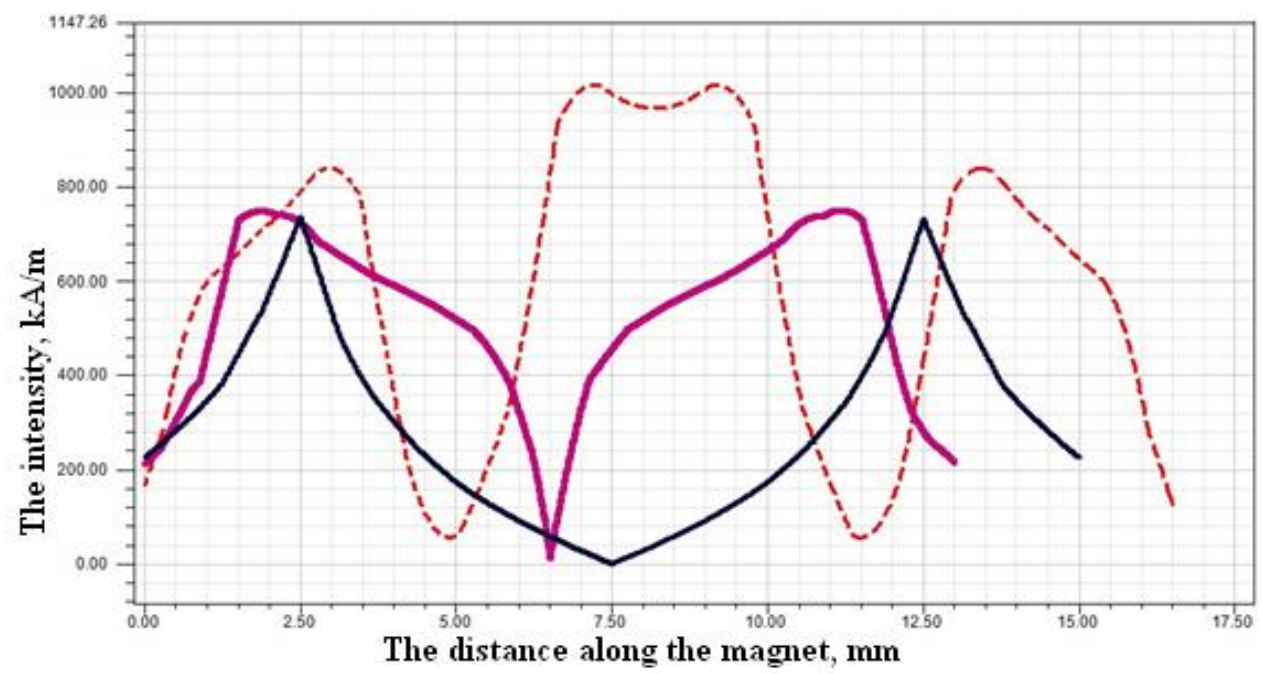

Fig. 4. Intensity of the magnetic field between the magnets $(0.5 \mathrm{~mm}$ from the surface of the magnet) at different magnetization ( angle of $45^{\circ}$, axial magnetization, and $n= \pm$ - Halbach assembly)

As seen (Fig. 4), the intensity between the levitating and support magnets is higher and more homogeneous in Halbach assembly. The Halbach assembly has a maximum intensity $35 \%$ greater than the intensity of 
magnetization at angle of $45^{\circ}$. Suspension as per Halbach assembly has two local minimal values of intensity that can be used to stabilize sustainability of the magnetic suspension.

Utilizing the finite element method in the software package ANSOFT Maxwell 3D, the repulsive forces between the levitating and permanent magnet in various suspension systems have been defined:

1. At axial magnetization - $1228.1 \mathrm{H}$.

2. At magnetization angle of $45^{\circ}-2495.9 \mathrm{H}$.

3. At Halbach assembly - 4391.9 N.

\section{IV.CONCLUSION}

Thus, in the compared systems of magnetizing of the permanent magnets in the conveyor with doublesuspension belt, the Halbach assembly consisting of axially magnetized magnets by interacting force exceeds the force of interaction by 1.75 times in the system with magnetization angle of $45^{\circ}$, and exceeds the force of interaction by 3.16 times in the system with axial magnetization with the same amount of magnetic material in the compared systems. Furthermore, it should be noted that the assembly of axially magnetized components of the permanent and levitating systems provides more favorable distribution of the magnetic field intensity to insure centering of the hard-magnet circuits. Therefore, applying the Halbach assembly principle at forming of permanent and levitating systems it is possible to significantly increase effectiveness of the magnetic suspension of the conveyor belt.

\section{REFERENCES}

[1] Pedchenko O.S., 2007. Opredelenie Geometricheskih Parametrov Zheloba Podvesnoj Konvejernoj Lenty [Determination of the Geometric Parameters of Trough of the Suspension Conveyor Belt] Gornyj inform.-analit. bjul. (nauch.-tehn. zhurn.). \#6, pp: 373376.

[2] Khan S., E. Kuru, D.K. Potter, 2015. Quantifying the Transport of Superparamagnetic Nanoparticles in Porous Media Using an Acrylic Flow Cell and Integrated Magnetic Susceptibility Sensor Technique Transport in Porous Media. T. 106. \#3, pp: 691705 .

[3] Zajcev A.A., 2014. Magnitolevitacionnye Transportnye Sistemy I Tehnologii [Magnitolevitatsionnye Transport Systems And Technologies Zheleznodorozhnyj Transport]. \#5, pp: 69-73.

[4] Coey J.M.D. Permanent Magnet Applications /Journal of Magnetism and Magnetic Materials. T. 248. \#3, pp: 441-456.

[5] Zacharov, A.Ju., 2005. Vlijanie Parametrov Bokovyh Blokov Postojannyh Magnitov na Cenrirovanie Lenty Konvejera na Magnitnoj Podushke [Influence of Lateral Block Parameters of the Permanent Magnets on the Central Magnetic Cushion Belt Conveyor]. Vestnik KuzSTU, \#1 (45), pp: 49-51.

[6] Zaharov A.Ju., A.G. Shkuratov, 2005. Jeksperimental'noe Issledovanie Vzaimodejstvija Lenty s Vertikal'nymi Rolikami Konvejera na Magnitnoj Podushke [Experimental Study of Interaction of the Belt with the Vertical Rollers of the Magnetic Cushion Conveyor] Gornyj inform.-analit. bjul. (nauch.-tehn. zhurn.), \#11, pp: 281-283.

[7] Zaharov A.Ju. 2008. Modeling of Cross-Section Displacement of the Magnetic Cushion Conveyor Belt / Advances in Geotechnical and Structural Engineering: proceedings of the Fifth China-Russia Symposium on Underground and Building Engineering of City and Mine, 26-28 Sept. 2008, Qingdao (China). - China University of Mining and Technology Press, pp: 63-65.

[8] Zaharov A.Ju., 2003. Konvejer Novogo Pokolenija dlja Transportirovanija Krupnokuskovoj Gornoj Massy [A New
Generation of Conveyor for Transportation of the Lumpy Rocks] Gornye Mashiny I Avtomatika. \#12, pp: 34-36.

[9] Peshkov, S.V., 2010. Opredelenie Special'nyh Harakteristik Jelementnyh Sostavljajushhih Konvej-Ernyh Lent [Defining of the Special Characteristics of the Elemental Parts of the Conveyor Belts] Vestnik Kuzbass. gosud. tehn. univ. \#1., pp: 136-138.

[10] Zacharov A.Ju., S.V. Peshkov, 2011. Issledovanie Silovogo Vzaimodejstvija Magnitozhestkoj Lenty Konvejera s Barabanom [Research of the Force Interact of the Hard-Magnet Conveyor Belt with a Drum] Gornyj inform.-analit. bjul. (nauch.-tehn. zhurn.). Vyp. 5(otd.): Perspektivy razvitija gorno-transportnogo oborudovanija, pp: 164-167.

[11] Zacharov A.Ju., S.V. Peshkov, 2006. Issledovanie Naprjazhennogo Sostojanija Vstroennogo Elementa V Konvejernuju Lentu pri Ee Dvizhenii [Research of the Stress Condition of the Built-In Element into Conveyor Belt at Motion] / Vestnik KuzSTU, \#6(57), pp: 40-41.

[12] Reutov A.A., K.A Goncharov, 2010. Analiz Sovmestno Raboti Koncevogo i Promejutochnogo Privodov Lentochnogo Konveiera. [Analysis of the Joint Work of the End Drive and Intermediate Drive of the Belt Conveyor]. Vestn. Bryanskogo gos. tehn. un_ta. \#2, pp: 42-45.

[13] Kruusing A., 2001. Optimizing Magnetization Orientation of Permanent Magnets for Maximal Gradient Force / A. Kruusing // Journal of Magnetism and Magnetic Materials, \#234, pp: 545-555.

[14] Janssen L.G.*, J. H. Paulides, L E. A.omonova, 2012. Study of Magnetic Gravity Compensator Topologies Using an Abstraction in the Analytical Interaction Equations. Progress in Electromagnetics Research, Vol. 128, 75\{90\}.

[15] Yonnet J.P., H. Allag, M.E.H. Latreche, 2008."2D and 3D Analytical Calculations of Magnet Interactions", MmdE conference, Bucarest.

[16] Yonnet J.P., H. Allag, M.E.H. Latreche, 2009. “3D Analytical Calculation of Forces between Linear Halbach Type Permanent Magnets Arrays", Electromotion Conference, Lille (F).

[17] Choi Y.M., M. Lee, G Gweon., D.G., Jeong J., 2009. A New magnetic Bearing Using Halbach Magnet Arrays for a Magnetic Levitation Stage," Review of Scientific Instruments, Vol. 80, \# $045106,1\{9\}$ 